\title{
PENILAIAN KELOMPOK TANI TERHADAP PELAKSANAAN FUNGSI PENYULUH PERTANIAN DI DESA TATENGESAN SATU KECAMATAN PUSOMAEN KABUPATEN MINAHASA TENGGARA (Studi Kasus : Kelompok Tani Marapuan Jaya dan Kelompok Tani Pasan Jaya)
}

\author{
Christofel Joshua Ngongoloy \\ Elsje Pauline Manginsela \\ Benu Olfie Liesje Suzana
}

\begin{tabular}{ll}
\hline Naskah diterima melalui Website Jurnal Ilmiah agrisosioekonomi@unsrat.ac.id & : Selasa, 15 Oktober 2019 \\
Disetujui diterbitkan & : Rabu, 23 Oktober 2019 \\
\hline
\end{tabular}

\begin{abstract}
This study aims to determine the assessment of farmer groups on the implementation of the function of agricultural instructors in the village of Tatengesan Satu, Pusomaen Sub-district, Southeast Minahasa Regency. This research was conducted from June to August 2019. The data used are primary data and secondary data. Primary data obtained by interview, based on questionaire, to two farmer groups, each chairman, secretary, treasurer and one member and one agricultural instructor. So that the total respondents were 9 people. Secondary data was obtained from relevant agencies namely through the Agricultural Extension Office (BPP), the Head of Village Office and the Pusomaen Sub-district Office of Southeast Minahasa Regency. Secondary data was also obtained through books obtained from local bookstores and the internet. From internet through google scholar in the form of books, journal articles and theses related to this research topic namely Assessment of Farmer Groups on the Implementation Function of Agriculture Extension. The results showed that the assessment of farmer groups on the implementation of the function of agricultural instructors is not yet fully functioning, where the new agricultural instructors carry out their functions as initiators, facilitators and motivators. While the function of extension workers as a liaison, analyzer and agent of change has not yet been fully felt by the farmer groups. But on the other hand, according to the agricultural instructor, it has been carrying out its functions to the maximum, it's just that the function as an agent of change cannot be fully carried out. This is because extension agents feel that farmers are able to make changes to advance their own farming business to make it more profitable. ${ }^{*}$ eprm*
\end{abstract}

Keywords: assessment, implementation, extension function, farmer

\begin{abstract}
ABSTRAK
Penelitian ini bertujuan untuk mengetahui penilaian kelompok tani terhadap pelaksanaan fungsi penyuluh pertanian di Desa Tatengesan Satu Kecamatan Pusomaen Kabupaten Minahasa Tenggara. Penelitian ini dilaksanakan dari bulan Juni sampai Agustus 2019. Data yang digunakan adalah data primer dan data sekunder. Data primer dikumpulkan melalui wawancara, berdasarkan kuesioner, kepada dua kelompok tani masing-masing ketua, sekertaris, bendahara dan satu orang anggota serta satu orang penyuluh pertanian. Sehingga total responden sebanyak 9 orang. Data sekunder diperoleh dari instansi terkait yaitu melalui Balai Penyuluh Pertanian (BPP), Kantor Hukum Tua dan Kantor Kecamatan Pusomaen Kabupaten Minahasa Tenggara. Data sekunder juga diperoleh melalui buku yang diperoleh dari toko buku lokal serta internet. Dari melalui google scholar berupa buku, artikel jurnal dan skripsi yang berkaitan dengan topik penelitian ini yaitu Penilaian Kelompok Tani Terhadap Pelaksanaan Fungsi Penyuluh Pertanian. Hasil penelitian menunjukkan bahwa penilaian kelompok tani terhadap pelaksanaan fungsi penyuluh pertanian belum sepenuhnya fungsi dimana penyuluh pertanian baru melaksanakan fungsinya sebagai inisiator, fasilitator dan motivator. Sedangkan fungsi penyuluh sebagai penghubung, penganalisa dan agen perubahan belum sepenuhnya dirasakan oleh kelompok tani. Namun dilain pihak, menurut penyuluh pertanian sudah menjalankan fungsinya dengan maksimal hanya saja fungsi sebagai agen perubahan masih belum bisa sepenuhnya dilakukan. Hal ini disebabkan penyuluh merasa petani mampu membuat perubahan untuk memajukan usaha tani mereka sendiri agar lebih menguntungkan. ${ }^{*}$ prm*
\end{abstract}

Kata kunci: penilaian, pelaksanaan, fungsi penyuluh, kelompok tani 


\section{PENDAHULUAN}

\section{Latar Belakang}

Pertanian merupakan salah satu sektor utama yang menopang kehidupan masyarakat, karena sektor pertanian menjadi mata pencaharian sebagian besar penduduk Indonesia. Selain itu juga, sektor pertanian menjadi salah satu pilar dalam menggerakan perekonomian Nasional. Berdasarkan data Badan Pusat Statistik 2018, penduduk yang bekerja di sektor pertanian tertinggi, berjumlah 38,70 juta orang atau 30,46 persen dari total usia produktif, sedangkan sisanya sebanyak 69,54 persen tersebar diberbagai sektor di luar pertanian.

Sektor pertanian sendiri dalam penerapannya terbagi menjadi lima, yaitu pertama sub-sektor tanaman pangan, kedua sub-sektor perkebunan, ketiga sub-sektor hortikultura, keempat sub-sektor peternakan dan kelima subsektor perikanan (Mubyarto, 2005). Keberhasilan di lima sub-sektor dipengaruhi oleh kegiatan penyuluhan pertanian dimaksudkan agar petani dan keluarganya mampu mencukupi kebutuhannya.

Penyuluhan pertanian merupakan pendidikan non-formal bagi petani dan keluarganya agar dapat bertani lebih baik, berusahatani yang lebih menguntungkan dan terwujudnya kehidupan yang lebih sejahtera bagi keluarga dan masyarakatnya (Mardikanto, 2009). Selain harus bisa membimbing para petani, penyuluh juga memberikan motivasi, memberikan informasi dan meningkatkan kesadaran petani sehingga dapat mendorong minat belajar mereka dalam menghadapi dan memecahkan permasalahan yang dihadapi.

Petani adalah pelaku utama, baik sebagai pengelola maupun pelaksana dalam kegiatan produksi pertanian serta merupakan bagian dari masyarakat Indonesia yang perlu ditingkatkan kesejahteraan dan kecerdasannya. Salah satu upaya peningkatan kecerdasan tersebut dilaksanakan melalui kegiatan penyuluhan. Dengan adanya penyuluh diharapkan semua perkembangan informasi pertanian dapat diteruskan pada petani. Semakin banyak informasi yang diterima dan dimanfaatkan oleh petani maka semakin efektif penyuluhan tersebut (Hasan, 2016). Subjek pembangunan pertanian adalah petani, masyarakat petani pada umumnya dan kelompok tani pada khususnya.
Sebagai salah satu komponen dalam sistem agribisnis, maka peran kelompok tani sangat menentukan keberhasilan penyuluhan. Penyuluh dapat mempengaruhi tujuan melalui fungsinya yang berperan sebagai inisiator, fasilitator, motivator, penghubung, penganalisa dan sebagai agen perubahan. Penyuluh pertanian membantu mencarikan informasi inovasi, permodalan, pemasaran, mengajarkan keterampilan, menawarkan paket teknologi, memfasilitasi dan mengembangkan swadaya dan swakarya petani (Noor, 2012).

Banyak kelompok tani telah dikembangkan, tetapi banyak pula yang mempertanyakan eksistensinya, seiring dengan adanya bantuan kredit, subsisidi sarana produksi, bantuan fisik, serta anjuran menerapkan teknologi. Tetapi fakta juga telah menunjukkan, dengan berakhirnya bantuan tersebut, maka berakhir pula kelompoknya dan anjuran teknologi mulai ditinggalkan, ini semua menunjukkan ada yang salah dengan upaya yang telah dilakukan selama ini.

Untuk itu diperlukan penyuluh pertanian yang konsisten dalam menjalankan fungsinya pada kelompok tani, sehingga dapat mendukung sistem agribisnis berbasis pertanian (tanaman pangan, hortikultura, peternakan dan perkebunan) (Sitepu, 2016). Kegiatan penyuluhan pertanian yang konsisten sangat penting didalam pembangunan pertanian, terutama di Negara yang sedang berkembang. Kerjasama antara penyuluh dengan kelompok tani sangat diperlukan untuk menghasilkan petani yang baik dan berkualitas, di Desa Tatengesan Satu Kecamatan Pusomaen, pemanfaatan lahan pertanian didominasi oleh tanaman pangan dan tanaman perkebunan yang terbentuk dalam Kelompok Tani Marapuan Jaya dan Kelompok Tani Pasan Jaya.

Namun, kinerja penyuluh pertanian di Desa Tatengesan Satu, dalam membantu para petani berusahatani padi, jagung, kelapa dan cengkih belum dilaksanakan secara maksimal sesuai dengan fungsinya. Dengan melihat latar belakang tersebut, maka dirasa perlu untuk dilakukan suatu penelitian dengan judul "Penilaian Pengurus Kelompok Tani Terhadap Pelaksanaan Fungsi Penyuluh Pertanian Di Desa Tatengesan Satu Kecamatan Pusomaen Kabupaten Minahasa Tenggara". 


\section{Rumusan Masalah}

Berdasarkan latar belakang yang telah dikemukakan, maka yang menjadi permasalahan dalam penelitian ini adalah bagaimana penilaian kelompok tani terhadap pelaksanaan fungsi penyuluh pertanian di Desa Tatengesan Satu Kecamatan Pusomaen Kabupaten Minahasa Tenggara.

\section{Tujuan penelitian}

Penelitian ini bertujuan untuk mengetahui penilaian kelompok tani terhadap pelaksanaan fungsi penyuluh pertanian di Desa Tatengesan Satu Kecamatan Pusomaen Kabupaten Minahasa Tenggara.

\section{Manfaat Penelitian}

Manfaat dalam penelitian ini adalah

1) Bagi peneliti dapat melatih cara berpikir sistematis dan penelitian ini merupakan salah satu syarat untuk memperoleh gelar sarjana di Fakultas Pertanian Universitas Sam Ratulangi, Manado.

2) Bagi penyuluh, untuk meningkatkan kinerja penyuluhan di Desa.

3) Bagi peneliti lain, dapat dijadikan referensi kajian dalam bidang penelitian yang sama.

\section{METODE PENELITIAN}

\section{Waktu dan Tempat Penelitian}

Penelitian ini dilaksanakan selama 3 bulan, dari bulan Juni sampai dengan bulan Agustus 2019, mulai dari persiapan sampai dengan penyusunan laporan hasil penelitian. Tempat penelitian dilaksanakan di Desa Tatengesan Satu, Kecamatan Pusomaen Kabupaten Minahasa Tenggara.

\section{Metode Pengumpulan Data}

Jenis data yang diambil adalah data primer dan data sekunder. Pengambilan data primer dilakukan dengan kuisioner dan wawancara kepada masyarakat petani dan penyuluh pertanian yang menjadi sampel penelitian menggunakan daftar pertanyaan yang telah disiapkan oleh peneliti. Data sekunder diperoleh dari instansi terkait yaitu melalui Balai Penyuluh Pertanian (BPP), Kantor Hukum Tua dan Kantor Kecamatan Pusomaen Kabupaten Minahasa Tenggara, buku, artikel, jurnal, internet.

\section{Metode Pengambilan Sampel}

Pengambilan sampel dalam penelitian ini menggunakan metode purposive sampling yaitu pengambilan data atau responden dilakukan secara sengaja dengan mempertimbangkan kriteria responden yang menjadi sampel adalah mereka yang masuk dalam kelompok tani baik sebagai ketua, sekretaris, bendahara dan juga anggota kelompok tani. Dalam penelitian ini jumlah sampel yang diambil sebanyak 9 orang responden, masing-masing 4 orang dari kelompok Tani Marapuan Jaya dan 4 orang dari kelompok Tani Pasan Jaya serta 1 orang penyuluh pertanian di Desa Tatengesan Satu.

\section{Konsep Pengukuran Variabel}

Variabel-variabel yang diteliti adalah :

1. Penyuluh sebagai inisiator

Yang senantiasa selalu memberikan gagasan/ide-ide baru.

2. Penyuluh sebagai fasilitator

Yang senantiasa memberikan jalan keluar/ kemudahan-kemudahan, baik dalam menyuluh maupun fasilitas dalam membangun atau memajukan usahantaninya. Dalam hal menyuluh Penyuluh memfasilitasi dalam hal: Kemitraan usaha, berakses ke pasar, permodalan dan sebagainya.

3. Penyuluh sebagai motivator

Penyuluh senantiasa membuat petani tahu, mau dan mampu.

4. Penyuluh sebagai penghubung

Dalam hal ini penyuluh sebagai penyampai aspirasi masyarakat tani, penyuluh sebagai penyampai kebijakan dalam peraturan bidang pertanian.

5. Penyuluh sebagai penganalisa

Penyuluh dituntut untuk mampu menganalisa masalah, sebab yang ada di usaha tani dan di keluarga tani mampu menganalisa kebutuhan petani.

6. Penyuluh sebagai agen perubahan

Penyuluh senantiasa harus dapat mempengaruhi sasarannya agar dapat merubah dirinya kearah kemajuan. Dalam hal ini penyuluh berperan sebagai katalis, pembantu memecahkan masalah, pembantu proses dan sebagai sumber penghubung. 
Adapun variabel-variabel penunjang lain sebagai berikut :

1. Umur Petani

2. Jenis Kelamin Petani

3. Pendidikan Petani

4. Jumlah Tanggungan Keluarga Petani

\section{Metode Analisis Data}

Data yang diperoleh dalam penlitian ini selanjutnya diolah dan dianalisis secara deskriptif kualitatif. Tahapan-tahapan dalam menganalisis data secara deskriptif kualitatif sebagai berikut :

1) Reduksi data, yaitu menyaring data yang diperoleh dilapangan yang masih ditulis dalam bentuk uraian atau laporan terperinci. Laporan tersebut direduksi, dirangkum, dipilih, difokuskan pada bantuan program, disusun lebih sistematis, sehingga muda dipahami.

2) Penyajian data, yaitu usaha untuk menunjukkan sekumpulan data atau informasi, untuk melihat gambaran keseluruhannya atau bagian tertentu dari penelitian tersebut.

3) Kesimpulan, merupakan proses untuk menjawab permasalahan dan tujuan sehingga ditentukan saran dan masukan untuk pemecahan masalah.

\section{HASIL DAN PEMBAHASAN}

\section{Deskripsi Wilayah Penelitian}

\section{Letak Geografis}

Letak Geografis Kecamatan Pusomaen merupakan Kecamatan termuda pada saat daerah Kabupatan Minahasa Tenggara dimekarkan dari Kabupaten Minahasa Selatan, dibentuk berdasarkan Peraturan Daerah Kabupaten Minahasa Selatan Nomor 18 Tahun 2005 Tentang Pembentukan Kecamatan Tatapaan, Amurang Barat, Amurang Timur, Maesaan, Pusomaen.

Kecamatan Pusomaen terdiri dari 15 desa, luas wilayah sebesar $5045 \mathrm{Ha}$ dengan jumlah penduduk 9.968 jiwa. Wilayah Kecamatan Pusomaen memiliki berbagai potensi yang dapat dikembangkan untuk pertumbuhan ekonomi masyarakat dan juga untuk menambah sumber-sumber pendapatan asli daerah Kabupaten Minahasa Tenggara terutama dalam bidang perikanan dan kelautan, pertanian dan perkebunan, peternakan dan pariwisata.

Sumber pendapatan dalam bidang Pertanian di Kecamatan Pusomaen antara lain tanaman padi sawah, yang merupakan sumber pendapatan utama masyarakat. Luas lahan 243,5 Ha. Angka ini merupakan akumulasi dari lahan persawahan yang dimiliki oleh 7 desa di Kecamatan Pusomaen. Hal ini dapat dilihat pada Tabel 1.

Tabel 1. Luas Lahan Persawahan dan Jumlah Petani di 7 Desa Kecamatan Pusomaen

\begin{tabular}{clcc}
\hline No & \multicolumn{1}{c}{ Desa } & $\begin{array}{c}\text { Luas Lahan } \\
\text { Persawahan }(\mathrm{Ha})\end{array}$ & Petani \\
\hline 1 & Minanga & 11 & 135 \\
2 & Minanga Timur & 23 & 195 \\
3 & Minanga 1 & 87 & 210 \\
4 & Minanga 2 & 65 & 135 \\
5 & Makalu & 46 & 195 \\
6 & Selatan & 60 & 195 \\
7 & Tatengesan & 10 & 275 \\
\hline & Tatengesan 1 & 243,5 & 1.340 \\
\hline
\end{tabular}

Sumber : Kantor Balai Penyuluhan Pertanian (BPP) Kec. Pusomaen, 2018

Desa Tatengesan Satu merupakan salah satu Desa yang terletak di Kecamatan Pusomaen dengan luas wilayah wilayah $894 \mathrm{Ha}$, yang terdiri dari empat jaga. Adapun batas-batas wilayah dari Desa Tatengesan Satu yaitu:

- Sebelah Utara

- Sebelah Selatan

- Sebelah Barat

- Sebelah Timur

Secara letak geografis Desa Tatengesan Satu memiliki ketinggian $300 \mathrm{Mdpl}$ (Meter dari permukaan laut), dengan kemiringan $60 \%$.

\section{Keadaan Penduduk}

Keseluruhan jumlah penduduk yang berada di Desa Tatengesan Satu 810 jiwa. Tabel 2 menunjukan jumlah penduduk berdasarkan jenis kelamin di Desa Tatengesan Satu.

Tabel 2. Jumlah Penduduk Berdasarkan Jenis Kelamin di Desa Tatengesan Satu

\begin{tabular}{|c|c|c|c|}
\hline No & Jenis Kelamin & Jumlah (Orang) & Persentase $(\%)$ \\
\hline 1 & Laki-Laki & 427 & 52,72 \\
\hline 2 & Perempuan & 383 & 47,28 \\
\hline & Jumlah & 810 & 100 \\
\hline
\end{tabular}

Sumber : Kantor Desa Tatengesan Satu, 2018

Tabel 2 menunjukkan jumlah penduduk berjenis kelamin, laki-laki sebanyak 427 jiwa $(52.72 \%)$ dan jumlah penduduk berjenis kelamin perempuan sebanyak 383 jiwa $(47.28 \%)$, yang tersebar dalam 4 (empat) jaga. 


\section{Jumlah Penduduk Berdasarkan Tingkat Pendidikan}

Jumlah penduduk berdasarkan tingkat pendidikan sebanyak 720 jiwa. Tabel 3 menunjukkan jumlah penduduk berdasarkan tingkat pendidikan yang ada di Desa Tatengesan Satu.

\begin{tabular}{cccr}
\multicolumn{4}{c}{ Tabel 3. Jumlah Penduduk Berdasarkan Tingkat Pendidikan } \\
\hline No & Tingkat Pendidikan & Jumlah (Orang) & Persentase (\%) \\
\hline 1 & Tamat SD & 398 & 55,28 \\
2 & Tamat SLTP/SMP & 120 & 16,67 \\
3 & Tamat SLTA/SMA & 173 & 24,03 \\
4 & Perguruan Tinggi & 29 & 4,02 \\
\hline \multicolumn{4}{c}{ Jumlah } \\
\hline Sumber $:$ Kantor Desa Tatengesan Satu, 2018
\end{tabular}

Tabel 3 menunjukkan jumlah penduduk berdasarkan tingkat pendidikan tertinggi pada pada tingkat SD sebanyak 398 orang $(55,28 \%)$ dan terendah pada perguruan tinggi sebanyak 29 orang $(4,02 \%)$.

\section{Jumlah Penduduk Berdasarkan Mata Pencaharian} Jumlah penduduk yang memiliki mata pencaharian sebanyak 344 jiwa. Tabel 4 menunjukkan jumlah penduduk berdasarkan mata pencaharian yang ada di Desa Tatengesan Satu.

\begin{tabular}{|c|c|c|c|}
\hline No & Jenis Pekerjaan & $\begin{array}{l}\text { Jumlah } \\
\text { (Orang) }\end{array}$ & Persentase (\%) \\
\hline 1 & Petani & 145 & 42,15 \\
\hline 2 & Buruh Tani & 62 & 17,44 \\
\hline 3 & Tukang & 30 & 8,72 \\
\hline 4 & Pengusaha & 7 & 2,03 \\
\hline 5 & Swasta & 43 & 12,5 \\
\hline 6 & PNS & 16 & 4,65 \\
\hline 7 & Buruh Bangunan & 22 & 6,40 \\
\hline 8 & Ojek & 9 & 2,62 \\
\hline 9 & Sopir & 5 & 1,45 \\
\hline 10 & Nelayan & 3 & 0,87 \\
\hline \multirow[t]{2}{*}{11} & Tukang Jahit & 2 & 0,58 \\
\hline & Jumlah & 344 & 100 \\
\hline
\end{tabular}

Sumber: Diolah dari data primer, 2019

\section{Kelompok Tani Responden}

\section{Profil Kelompok-Kelompok Tani Responden Desa Tatengesan Satu}

Terbentuknya kelompok tani bermula dari beberapa orang petani yang melakukan usaha pertanian/budidaya tanaman pangan dan hortikultura dengan cara bergotong-royong secara bergantian diantara anggota tersebut atau yang biasa disebut konsi. Mulai dari pengolahan lahan, penyiangan sampai pasca panen. Dengan seringnya dilakukan kegiatan konsi tersebut, maka muncul pemikiran niat dan pemikiran sebagian anggota konsi untuk menjadikan kelompok konsi menjadi sebuah kelompok tani (Resicha, 2016). Desa Tatengesan Satu memiliki dua kelompok konsi, yaitu Kelompok Tani Marapuan Jaya didirikan pada tahun 2007 dan Kelompok Tani Pasan Jaya didirikan pada tahun 2011, kedua kelompok tani tersebut mengusahakan tanaman padi, jagung, kelapa dan cengkih.

\section{Karakteristik Petani Responden}

a. Umur Petani Responden

Cara berpikir seseorang, kemampuan dalam bekerja, atau melakukan aktivitas secara fisik di pengaruhi oleh faktor umur. Petani yang memiliki umur yang lebih muda memiliki kondisi fisik lebih kuat dari pada petani yang berumur lebih tua. Distribusi petani responden berdasarkan umur di sajikan pada Tabel 5.

Tabel 5. Distribusi Petani Responden Berdasarkan Umur

\begin{tabular}{|c|c|c|c|}
\hline No & Umur & Jumlah (Orang) & Persentase (\%) \\
\hline 1 & $<30$ & - & \\
\hline 2 & $31-40$ & 2 & 22,2 \\
\hline 3 & $41-50$ & 4 & 44,4 \\
\hline 4 & $>51$ & 3 & 33,3 \\
\hline & Jum & 9 & 100 \\
\hline
\end{tabular}

Sumber: Diolah dari data primer, 2019

Umur petani responden termuda umur 31 tahun sedangkan tertua umur 71 tahun. Tabel 5 menunjukkan persentase tertinggi responden pada usia $41->50$ tahun $(44,4 \%)$ dan terendah responden pada usia 31 - 40 tahun $(22,2 \%)$ responden.

\section{Jumlah Petani Berdasarkan Jenis Kelamin}

Jenis kelamin merupakan dalah satu faktor penentu dalam bekerja. Laki-laki biasanya memiliki kemampuan fisik lebih kuat dibandingkan perempuan. dari hasil penelitian di Desa Tatengesan jumlah petani laki-laki lebih banyak dari petani perempuan. Distribusi petani responden berdasarkan jenis kelamin di sajikan pada Tabel 6 .

Tabel 6. Distribusi Petani Responden Berdasarkan Jenis Kelamin

\begin{tabular}{clcc}
\hline No & Jenis Kelamin & Jumlah (Orang) & Persentase (\%) \\
\hline 1 & Laki-Laki & 8 & 88,8 \\
2 & Perempuan & 1 & 11,1 \\
\hline & Jumlah & 9 & 100 \\
\hline
\end{tabular}

Sumber: Diolah dari data primer, 2019

Tabel 6 menunjukkan bahwa jumlah petani responden berjenis kelamin laki-laki lebih banyak berjumlah 7 orang $(88,8 \%)$, dan responden yang berjenis kelamin perempuan berjumlah 1 orang $(11,1 \%)$. 


\section{Jumlah Petani Responden Berdasarkan Tingkat Pendidikan}

Pendidikan formal sangat penting dalam peningkatan kualitas seseorang dalam cara berpikir, peningkatan intelektual dan wawasan seseorang. Berdasarkan hasil penelitian, tingkat pendidikan petani di Desa Tatengesan Satu dari Sekolah Dasar (SD), Sekolah Menengah Pertama (SLTP/SMP), Sekolah Menengah Atas (SLTA/SMA) dan Perguruan Tinggi. Distribusi petani responden berdasarkan tingkat pendidikan dapat dilihat pada Tabel 7.

Tabel 7. Distribusi Petani Responden Berdasarkan Tingkat Pendidikan

\begin{tabular}{clcr}
\hline No & Tingkat Pendidikan & Jumlah (Orang) & Persentase (\%) \\
\hline 1 & Tamat SD & 1 & 11,1 \\
2 & Tamat SLTP/SMP & 1 & 11,1 \\
3 & Tamat SLTA/SMA & 5 & 55,5 \\
4 & Perguruan Tinggi & 2 & 22,2 \\
\hline & Jumlah & 9 & 100 \\
\hline
\end{tabular}

Sumber: Diolah dari data primer, 2019

Tabel 7 menunjukkan bahwa distribusi petani responden berdasarkan tingkat pendidikan terbanyak pada tingkat SLTA/SMA berjumlah 4 orang $(55,5 \%)$ responden, dan tersedikit pada tingkat SD SLTP/SMP masing-masing berjumlah 1 orang $(11,1 \%)$ responden. Sudah ada petani yang lulus Perguruan Tinggi.

\begin{tabular}{|c|c|c|c|}
\hline Tabel & $\begin{array}{l}\text { 8. } \underset{\text { Tumlah } P}{\text { Tanggungar }} \\
\text { Jang }\end{array}$ & $\begin{array}{l}\text { Petani Responden } \\
\text { in Keluarga }\end{array}$ & menurut Jumlah \\
\hline No & $\begin{array}{l}\text { Jumlah Anggota } \\
\text { Keluarga (Orang) }\end{array}$ & Responden & Persentase (\%) \\
\hline 1 & $<2$ & 4 & 44,4 \\
\hline 2 & $3-4$ & 5 & 55,5 \\
\hline 3 & 5 & - & \\
\hline & Jumlah & 9 & 100 \\
\hline
\end{tabular}

Sumber: Diolah dari data primer, 2019

Tabel 8 menunjukkan bahwa petani responden menurut jumlah tanggungan keluarga terbanyak 4 orang dan tersedikit 3 orang. Tabel 8 menunjukkan persentase tertinggi responden pada jumlah tanggungan $3-4$ orang $(55,5 \%)$ dan terendah responden pada jumlah tanggungan $<2$ orang $(44,4 \%)$ responden.

\section{Penilaian Kelompok Tani Terhadap Pelaksanaan Fungsi Penyuluh Pertanian}

\section{Fungsi Penyuluh Sebagai Inisiator}

Penyuluh sebagai inisiator harus bertindak antara lain memberikan gagasan/ide-ide baru dan melatih keterampilan petani terhadap ide tersebut. Fungsi penyuluh sebagai inisiator dapat dilihat pada Tabel 9.
Tabel 9. Fungsi Penyuluh Pertanian Sebagai Inisiator

\begin{tabular}{|c|c|c|c|}
\hline No & $\begin{array}{c}\text { Petani } \\
\text { Responden }\end{array}$ & Ya/Tidak & Penjelasan \\
\hline 1 & $\mathrm{SN}$ & Ya & $\begin{array}{l}\text { Cara bercocok tanam tanaman padi } \\
\text { misalnya, harus legowo dengan cara } \\
212 \text { atau } 23 \text { secara berjejer. }\end{array}$ \\
\hline 2 & NI & Ya & $\begin{array}{l}\text { Cara menanam jagung yang baik, } \\
\text { supaya mendapatkan hasil yang } \\
\text { baik. }\end{array}$ \\
\hline 3 & DP & Tidak & $\begin{array}{l}\text { Penyuluh tidak pernah memberikan } \\
\text { gagasan/ide-ide. }\end{array}$ \\
\hline 4 & ML & Ya & $\begin{array}{l}\text { Pemberian pupuk yang tepat pada } \\
\text { tanaman .jagung }\end{array}$ \\
\hline 5 & YL & Tidak & $\begin{array}{l}\text { Gagasan/ide-ide hanya dari dalam } \\
\text { kelompok tani. }\end{array}$ \\
\hline 6 & $\mathrm{JL}$ & Ya & $\begin{array}{l}\text { Pada program Mina } \begin{array}{r}\text { Padi, } \\
\text { menggunakan jaring } \\
\text { penangkal burung. }\end{array}\end{array}$ \\
\hline 7 & SU & Ya & $\begin{array}{l}\text { Ide untuk menanam secara serentak } \\
\text { agar tidak diserang hama. }\end{array}$ \\
\hline 8 & JW & Ya & Hanya untuk tanaman padi. \\
\hline
\end{tabular}

Tabel 9 menunjukkan fungsi penyuluh sebagai inisiator, petani responden yang menyatakan penyuluh pernah memberikan gagasan/ide-ide baru, berjumlah 6 orang sedangkan 2 orang lainnya menyatakan penyuluh tidak pernah memberikan gagasan/ide-ide baru.

\section{Fungsi Penyuluh Sebagai Fasilitator}

Penyuluh sebagai fasilitator harus bisa bertindak antara lain memfasilitasi para petani dalam hal membangun usaha tani. Fungsi penyuluh pertanian sebagai fasilitator dapat dilihat pada Tabel 10.

Tabel 10. Fungsi Penyuluh Pertanian Sebagai Fasilitator

\begin{tabular}{|c|c|c|c|}
\hline No & $\begin{array}{c}\text { Petani } \\
\text { Responden }\end{array}$ & Ya/Tidak & Penjelasan \\
\hline 1 & SN & Ya & $\begin{array}{l}\text { Seperti pupuk, benih dan alat-alat } \\
\text { pertanian. }\end{array}$ \\
\hline 2 & NI & Ya & $\begin{array}{l}\text { Pemberian fasilitas berupa bantuan } \\
\text { bibit cengkih, pala dan lain-lain. }\end{array}$ \\
\hline 3 & DP & Ya & $\begin{array}{l}\text { Pemberian fasilitas alat rontok } \\
\text { jagung, bibit cengkih, pala dan } \\
\text { lain-lain. }\end{array}$ \\
\hline 4 & ML & Ya & $\begin{array}{l}\text { Pemberian pupuk, obat-obatan, } \\
\text { bibit cengkih, jagung serta kelapa. }\end{array}$ \\
\hline 5 & YL & Tidak & $\begin{array}{l}\text { Dulu pernah, sekarang sudah tidak } \\
\text { ada. }\end{array}$ \\
\hline 6 & $\mathrm{JL}$ & Ya & $\begin{array}{l}\text { Tetapi, hanya komoditas padi } \\
\text { seperti pupuk dan benih. }\end{array}$ \\
\hline 7 & SU & Ya & $\begin{array}{l}\text { Pemberian bantuan bibit, pupuk, } \\
\text { mesin dan lain-lain. }\end{array}$ \\
\hline 8 & JW & Ya & $\begin{array}{l}\text { Pemberian bibit padi, jagung dan } \\
\text { lain-lain. }\end{array}$ \\
\hline
\end{tabular}

Sumber: Data primer, 2019

Tabel 10 menunjukkan fungsi penyuluh sebagai fasilitator, petani responden yang menyatakan penyuluh pernah memfasilitasi dalam membangun usaha tani, berjumlah 7 orang sedangkan 1 orang lainnya menyatakan penyuluh tidak pernah memfasilitasi dalam membangun usaha tani. 


\section{Fungsi Penyuluh Sebagai Motivator}

Penyuluh sebagai motivator harus selalu memberikan dorongan/semangat kepada petani untuk terus maju. Fungsi penyuluh pertanian sebagai motivator dapat dilihat pada Tabel 11.

$\underline{\text { Tabel 11. Fungsi Penyuluh Pertanian Sebagai Motivator }}$

\begin{tabular}{|c|c|c|c|}
\hline No & $\begin{array}{c}\text { Petani } \\
\text { Responden }\end{array}$ & Ya/Tidak & Penjelasan \\
\hline 1 & SN & Ya & $\begin{array}{l}\text { Ketika datang bantuan itu } \\
\text { ditindaklanjuti oleh penyuluh } \\
\text { memberikan motivasi. }\end{array}$ \\
\hline 2 & NI & Ya & $\begin{array}{l}\text { Pernah tetapi sudah lama, dan } \\
\text { selama ini baru } 3 \text { kali. }\end{array}$ \\
\hline 3 & DP & Ya & Menanam padi secara bersamaan. \\
\hline 4 & ML & Ya & $\begin{array}{l}\text { Penyuluh pernah memberitahu } \\
\text { bagaimana cara bertani yang baik. }\end{array}$ \\
\hline 5 & YL & Ya & Pernah tetapi sudah berhenti. \\
\hline 6 & JL & Ya & $\begin{array}{l}\text { Senantiasa memberitahu agar } \\
\text { petani menjadi lebih baik. }\end{array}$ \\
\hline 7 & SU & Tidak & $\begin{array}{l}\text { Penyuluh lebih memilih } \\
\text { melakukan tugas lainnya. }\end{array}$ \\
\hline 8 & JW & Tidak & Penyuluh hanya memfasilitasi. \\
\hline
\end{tabular}

Tabel 11 menunjukkan fungsi penyuluh sebagai motivator, petani responden yang menyatakan penyuluh pernah membuat petani mau dan mampu dalam hal bertani yang baik, berjumlah 6 orang sedangkan 2 orang lainnya menyatakan penyuluh tidak pernah membuat petani mau dan mampu dalam hal bertani yang baik.

\section{Fungsi Penyuluh Sebagai Penghubung}

Penyuluh sebagai penghubung harus menyampaikan aspirasi dan percepatan informasi secara timbal balik antara petani dan pemerintah. Fungsi penyuluh pertanian sebagai penghubung dapat dilihat pada Tabel 12.

Tabel 12. Fungsi Penyuluh Pertanian Sebagai Penghubung

\begin{tabular}{|c|c|c|c|}
\hline No & $\begin{array}{c}\text { Petani } \\
\text { Responden }\end{array}$ & Ya/Tidak & Penjelasan \\
\hline 1 & SN & Ya & $\begin{array}{l}\text { Pernah seperti kami mengeluh harus } \\
\text { ada mesin rontok milu (jagung). } \\
\text { Penyuluh senantiasa menyampaikan } \\
\text { itu pada dinas dan akhirnya melalui } \\
\text { proses permintaan itu diwujudkan. }\end{array}$ \\
\hline 2 & NI & Ya & $\begin{array}{l}\text { Permintaan untuk mendapatkan } \\
\text { pupuk, pernah disampaikan ke dinas } \\
\text { terkait. }\end{array}$ \\
\hline 3 & $\mathrm{DP}$ & Ya & $\begin{array}{l}\text { Pengajuan permohonan dari petani } \\
\text { dengan cepat disampaikan kepada } \\
\text { dinas terkait. }\end{array}$ \\
\hline 4 & ML & Ya & $\begin{array}{l}\text { Beberapa kali, salah satunya } \\
\text { permintaan bibit cengkih dari } \\
\text { kelompok tani. }\end{array}$ \\
\hline 5 & YL & Ya & Untuk mengembangkan kelompok. \\
\hline 6 & $\mathrm{JL}$ & $\mathrm{Ya}$ & Permintaan benih ikan. \\
\hline 7 & SU & Ya & $\begin{array}{l}\text { Aspirasi meminta mesin rontok } \\
\text { jagung dan dinas memenuhinya. }\end{array}$ \\
\hline 8 & JW & $\mathrm{Ya}$ & Aspirasi untuk permintaan pupuk. \\
\hline
\end{tabular}

Tabel 12 menunjukkan fungsi penyuluh sebagai penghubung, semua petani responden menyatakan bahwa penyuluh pernah menyampaikan aspirasi/keinginan dari petani kepada dinas terkait.

\section{Fungsi Penyuluh Sebagai Penganalisa}

Penyuluh sebagai penganalisa harus mampu memecahkan masalah dan menjelaskan keuntungan serta keunggulan dari usahatani yang dilakukan. Fungsi penyuluh pertanian sebagai penganalisa dapat dilihat pada Tabel 13 .

\begin{tabular}{|c|c|c|c|}
\hline No & $\begin{array}{c}\text { Petani } \\
\text { Responden }\end{array}$ & Ya/Tidak & Penjelasan \\
\hline 1 & SN & Tidak & $\begin{array}{l}\text { Kalau soal menganalisapenyuluh tidak } \\
\text { pernah. }\end{array}$ \\
\hline 2 & NI & Tidak & $\begin{array}{l}\text { Penyuluh hanya lebih ke memberikan } \\
\text { motivasi kalau menganalisa tidak. }\end{array}$ \\
\hline 3 & DP & Tidak & Penyuluh tidak pernah menganalisa. \\
\hline 4 & ML & Tidak & Tidak pernah kalau menganalisa. \\
\hline 5 & YL & Tidak & Belum pernah melakukan analisa. \\
\hline 6 & $\mathrm{JL}$ & Tidak & $\begin{array}{l}\text { Untuk menganalisa penyuluh tidak } \\
\text { pernah. }\end{array}$ \\
\hline 7 & SU & Tidak & Penyuluh tidak pernah menganalisa. \\
\hline 8 & JW & Tidak & Penyuluh tidak pernah menganalisa. \\
\hline
\end{tabular}

Tabel 13 menunjukkan fungsi penyuluh sebagai penganalisa, hampir semua petani responden menyatakan bahwa penyuluh tidak pernah menganalisa dengan baik apa yang terjadi dalam kelompok tani.

\section{Fungsi Penyuluh Sebagai Agen Perubahan}

Penyuluh sebagai agen perubahan harus memberikan solusi yang konkret bagi petani dalam rangka pemecahan masalah dilingkungan kelompok tani. Fungsi penyuluh pertanian sebagai agen perubahan dapat dilihat pada Tabel 14 .

\begin{tabular}{|c|c|c|c|}
\hline No & $\begin{array}{c}\text { Petani } \\
\text { Responden }\end{array}$ & Ya/Tidak & Penjelasan \\
\hline 1 & $\mathrm{SN}$ & Tidak & $\begin{array}{l}\text { Kalau memecahkan masalah hanya } \\
\text { kami dari kelompok. }\end{array}$ \\
\hline 2 & NI & Ya & $\begin{array}{l}\text { Dalam memecahkan masalah hama } \\
\text { pada padi, penyuluh memberitahu } \\
\text { untuk menanam secara bersamaan. }\end{array}$ \\
\hline 3 & DP & Tidak & Hanya dari dalam kelompok tani. \\
\hline 4 & ML & Tidak & $\begin{array}{l}\text { Semua masalah hanya diselesaikan } \\
\text { oleh kelompok tani. }\end{array}$ \\
\hline 5 & YL & Tidak & Hanya dari kelompok tani. \\
\hline 6 & JL & Tidak & $\begin{array}{l}\text { Hanya dari kelompok tani yang } \\
\text { mencari jalan keluar. }\end{array}$ \\
\hline 7 & SU & Tidak & $\begin{array}{l}\text { Hanya kami anggota kelompok tani } \\
\text { yang mencari solusi jika ada } \\
\text { masalah. }\end{array}$ \\
\hline 8 & JW & Tidak & $\begin{array}{l}\text { Hanya kami anggota kelompok yang } \\
\text { mencari jalan keluar. }\end{array}$ \\
\hline
\end{tabular}

Sumber: Data primer, 2019 
Tabel 14 menunjukkan bahwa fungsi penyuluh sebagai agen perubahan, petani responden yang menyatakan penyuluh pernah membantu dalam memecahkan masalah, berjumlah 1 orang sedangkan 7 orang lainnya termasuk dari pihak penyuluh menyatakan tidak pernah membantu dalam memecahkan masalah.

\section{Penilaian Penyuluh Terhadap Pelaksanaan Fungsi Penyuluh Pertanian}

Penyuluh pertanian berkedudu-kan sebagai pelaksana teknis fungsional penyuluhan pertanian pada instansi pemerintah baik di tingkat pusat maupun daerah. Penyuluh pertanian dimaksud hanya dapat diduduki oleh seorang yang telah berstatus sebagai Pegawai Negeri Sipil. Penilaian penyuluh terhadap pelaksanaan fungsi penyuluh pertanian dapat dilihat pada Tabel 15.

\begin{tabular}{|c|c|c|c|}
\hline Tabel 15. & $\begin{array}{l}\text { Penilaian } \mathbf{P} \\
\text { Penyuluh } \mathbf{P e}\end{array}$ & $\begin{array}{l}\text { luh Ter } \\
\text { lian }\end{array}$ & adap Pelaksanaan Fungsi \\
\hline $\begin{array}{r}\text { Penyuluh } \\
\text { Responden }\end{array}$ & $\begin{array}{l}\text { Fungsi } \\
\text { Penyuluh }\end{array}$ & Ya/Tidak & Pelaksanaan \\
\hline \multirow{6}{*}{ MN } & Inisiator & Ya & $\begin{array}{l}\text { Seperti cara menanam, cara } \\
\text { menghitung berapa banyak } \\
\text { benih yang harus dipakai } \\
\text { dalam jumlah berapa Ha. }\end{array}$ \\
\hline & Fasilitator & Ya & $\begin{array}{l}\text { Misalnya benih jagung, } \\
\text { cengkih, kelapa serta obat- } \\
\text { obatan, pupuk dan mesin. }\end{array}$ \\
\hline & Motivator & Ya & $\begin{array}{l}\text { Untuk kelompok-kelompok } \\
\text { tersebut, misalnya bila ingin } \\
\text { maju harus kompak, berani } \\
\text { mengambil resiko dalam } \\
\text { bertani, supaya pertanian } \\
\text { maju. }\end{array}$ \\
\hline & Penghubung & $\mathrm{Ya}$ & $\begin{array}{l}\text { Selalu aspirasi dari petani } \\
\text { kami tindak lanjuti pada } \\
\text { dinas, misalnya permintaan } \\
\text { mesin sampai benih ikan. }\end{array}$ \\
\hline & Penganalisa & Ya & $\begin{array}{l}\text { Misalnya menganalisa berapa } \\
\text { pendapatan bertani selama } 3 \\
\text { bulan khusus untuk kelapa, } \\
\text { dan padi. }\end{array}$ \\
\hline & $\begin{array}{l}\text { Agen } \\
\text { Perubahan }\end{array}$ & Tidak & $\begin{array}{l}\text { Karena saya merasa petani } \\
\text { sudah cukup dewasa untuk } \\
\text { menyelesaikan masalah yang } \\
\text { mereka hadapi dan selama ini } \\
\text { juga, mereka tidak pernah } \\
\text { meminta bantuan dari } \\
\text { penyuluh jika terjadi masalah. }\end{array}$ \\
\hline
\end{tabular}

\section{KESIMPULAN DAN SARAN}

\section{Kesimpulan}

Berdasarkan penelitian yang telah dilakukan pada Penilaian Kelompok Tani Terhadap Pelaksanaan Fungsi Penyuluh Pertanian Di Desa Tatengesan Satu Kecamatan Pusomaen Kabupaten Minahasa Tenggara, dapat disimpulkan belum berfungsi dengan baik. Hal ini dapat dilihat dari respon petani terhadap kontribusi penyuluh dalam setiap kegiatan kelompok tani, dimana penyuluh pertanian hanya menjalankan kebanyakan fungsinya sebagai inisiator, fasilitator dan motivator. Sedangkan fungsi penyuluh sebagai penghubung, penganalisa dan agen perubahan belum dirasakan oleh kelompok tani. Namun dilain pihak, menurut penyuluh pertanian sudah menjalankan fungsinya dengan maksimal hanya saja fungsi sebagai agen perubahan masih belum bisa membantu, karena penyuluh merasa petani sudah cukup dewasa dan petani juga tidak pernah meminta bantuan penyuluh dalam memecahkan masalah di kelompok.

\section{Saran}

Fungsi penyuluh sebagai penghubung, penganalisa dan agen perubahan pada kelompok tani harus lebih dimaksimalkan agar terwujud kelompok tani yang mandiri dan maju. Untuk mengatasi kendala dilapangan diperlukan juga campur tangan dari pemerintah daerah, seperti penambahan tenaga kerja penyuluh dari dinas terkait. Selain itu, perlu dilakukan penelitian lebih lanjut untuk mengetahui penyebab perbedaan pendapat tentang fungsi penyuluh pertanian dari para petani dengan penyuluh.

\section{DAFTAR PUSTAKA}

Badan Pusat Statistik, 2018. Penduduk Yang Bekerja di Sektor Pertanian.

Hasan, 2016. Pengaruh Penyuluhan Pertanian Dalam Aspek Lingkungan, Ekonomi Dan Teknologi Pada Petani Padi Sawah Di Kecamatan Modayag. Skripsi. Fakultas Pertanian Universitas Sam Ratulangi.

Mardikanto, 2009. Sistem Penyuluhan Pertanian. Surakarta : University Sebelas Maret Press.

Noor, 2012. Buku Pintar Penyuluh Pertanian. Jakarta : PERHIPTANI (Perhimpunan Penyuluh Pertanian Indonesia).

Resicha, 2016. Peran Penyuluh Pertanian Dalam Pengembangan Kelompok Tani di Nagari Sungai Pua Kecamatan Sungai Pua Kabupaten Agam. Jurnal. Fakultas Pertanian Universitas Andalas.

Sitepu, 2016. Peran Penyuluh Pertanian Dalam Pengembangan Kelompok Tani di Kecamatan Barus Jahe. Jurnal. Fakultas Pertanian Universitas Sumatera Utara. 